\title{
Children's Experiences of the Coal Mine Disaster: Analysis of Junior High School Students' Essays in Yubari City
}

\author{
Ryota Kasahara \\ PhD Student, Waseda University, Tokyo, Japan
}

\begin{abstract}
In 1981, a gas outburst accident occurred in the Yubari Shintanko coal mine, the only expectant mine in Japan, it caused 93 deaths. As a result, Yubari Shintanko closed in 1982. This major disaster was a turning point for sustainability of Yubari City, the largest coalfield in Japan. Finally, Yubari City was bankrupted in 2007. This paper aims to explore how miner's children experienced this disaster and felt about region, family, and themselves, and to explain the relation between region declining and children's lives. The data of this paper are the archived 600 essays, written by the junior high school students at the time of the disaster. There are three findings. First, the children who lost their father were the most shocked. They faced profound sadness. But they expressed that they had decided to overcome their sadness with surviving family. Second, the children who didn't lose their father were also influenced. They were anxious about the future of Yubari, their family, and themselves. Furthermore, they decided to strive for their future. Third, they understood the disaster as a turning point of Yubari declining and looked ahead their future outside of Yubari. In conclusion, this disaster created their hopelessness to Yubari region and, as a result, promoted the decline of the city through their migration to other city. Furthermore, it is important to clarify that Yubari City has to continue the struggle to the regeneration.
\end{abstract}

Keywords: coal mine disaster, miner's children, essays, hopelessness, migration, region declining

\section{Introduction: Purpose of This Paper}

On October 16, 1981, a gas outburst accident occurred at the Hokutan Yubari New Coal mine (hereinafter referred to as the Yubari Shintanko), which was viewed as the expectation of the Japanese coal industry, claiming the lives of as many as 93 people. This was the third-largest disaster in the history of the Japanese coal industry in the postwar period. This accident determined the decline of the Japanese coal industry and the Yubari region. Around 20 years after the accident, the coal industry breathed its last breath and Yubari City was pushed to fiscal collapse.

However, it was not only the industry or the region that was hit hard by the accident. The accident also had a huge impact on miners and their families, including children. Especially, children in their adolescence were considerably affected by the accident as it occurred during a critical time in the formation of their life courses (Clausen 1986).

Until now, studies focusing on the relationship between the decline of industries or regions and children have been conducted in such fields as pedagogy and educational sociology (Shindo 2015), but few have been conducted through a life course approach in Japan. Although some studies paid attention to the period of transition to adulthood (Masaoka et al 1998-2007), they merely identified the overview of the transition and stopped short of shedding light on children's specific experiences and the dynamics of their lives. As this has been handled in foreign life course studies as a major field (for example, Elder 1974), there are expectations for progress in Japan as well.

Therefore, this paper examines the short-term impact that the accident had on local children's life courses using personal documents (essays) written by the children affected by the accident. What did the children think and what future did they envision as they witnessed the decline of their home town after the coalmine, which was the expectation of the coal industry, was suddenly shaken by the accident?

\section{Yubari City and the Yubari Shintanko 2.1 Yubari city as a coal community}

The City of Yubari used to be a coal community owing its development to the coal industry. As coal produced in Yubari coal field was of good quality and abundant coal reserves were available there, major coal companies pushed ahead with the development of mines after a colliery was established in 1891 by Hokkaido Colliery and Railway Company (hereinafter referred to as Hokutan). In the postwar peak period (1950s), around 20,000 miners were working at a total 20 mines in Yubari field (for example, the Hokutan Yubari mine, the Mitsubishi Oyubari mine). Yubari's population also increased, surpassing 100,000 people around that time (Hokkaido Shimbun (ed.) 2003). As the number of children had also grown, there were 22 elementary schools and 9 junior high schools in the city (Hokkaido 1959-1975). The schools, which were located near the area where residences for miners were concentrated, were called "mammoth schools" because of their very large

* Corresponding Author: R. Kasahara, kasahara.2369.bz@gmail.com, phone: +8190-6799-0423

Copyright @ 2017 Canamaple Academia Services, http://press.camdemia.ca

DOI: $10.15273 /$ gree.2017.02.046 
number of students. When the coal mines were prosperous, mine companies were closely involved with the schools, contributing to the improvement of the facilities and environment of the schools.

On the other hand, as Yubari is located in a narrow mountainous area with no broad hinterland around it and with poor traffic access, supporting industries did not develop. Consequently, Yubari's fortunes changed in tandem with the rise and fall of the coal industry. Yubari City withered because of the coal industry's rationalization and decline caused the energy revolution from the latter half of the 1950s onwards. In the 1960s, the mining areas were realigned and small and medium-size mines were closed one after another, and in the 1970s, mines with annual production of 500,000 tons were also closed (Yada 1983).

In line with the succession of mine closures, a population migration out of Yubari City proceeded, and in the first half of the 1970 s, the city's population was already smaller than 70,000 people (Yubari City 1981). As a result, some residential areas for miners shrank or disappeared. As Yubari's fiscal condition was dependent on coal mines, it rapidly deteriorated. While aiming for a shift to other industries such as tourism, the city was hoping for the revival of the coal industry and the development of new mines.

\subsection{New mine emerging as expectation}

Under these circumstances, Hokutan abandoned coal resources of good quality in northern Yubari, closing its mines there, and bet its fortunes on the development of a new mine producing coking coal of good quality in southern Yubari. That was the Yubari Shintanko. This mine, which was developed with the Development Funds provided by the government, was an expectation for the declining coal industry (Yubari City 1981). Hokutan aimed to achieve production mechanization and ensure safety with a view to creating one of the leading coal mines in Japan with daily production of 5,000 tons, annual production of 1.5 million tons and a production efficiency of 96.5 tons (per month per worker). Miners were concentrated at the Yubari Shintanko and a new town was built for them (Hokutan Yubari Coal Mine Labor Union 1983).

Hokutan ramped up miners' motivation through internal newsletters, while miners moved to the Yubari Shintanko from other mines with high expectations. Furthermore, not only miners but also their wives and children were pinning expectations on the Yubari Shintanko. At Seiryo Elementary School, attended by children of miners at the Yubari Shintanko, a collection of essays written by parents and children, titled Shinko (Yubari Shintanko), was published (Seiryo Elementary School 1971). The Yubari Shintanko was developed amid high expectations among the government, industry, the company, and miners and their families, and it started commercial coal production in 1975.

\subsection{Outline of the gas outburst accident}

However, the situation of the Yubari Shintanko continued to be severe right from the beginning of development, as the coal production volume remained short of the target (concerning the sequence of events from the development to the accident, refer to Table 1). As the extraction area was 1,000 meters deep underground and methane gas was seeping out in large volume, a succession of accidents, including gas outburst accidents, occurred. The management situation further deteriorated, making it urgent to develop a new mining area to rebuild the Yubari Shintanko. As a result, safety in the workplace was gradually neglected.

On October 16, 1981, the fatal gas outburst accident occurred. The fire broke out within the shaft at night, and in the small hours of the following morning, the president proposed to inject water into the shaft even while miners were trapped there. However, in response to adamant opposition from the labor union and families, the water injection proposal was withdrawn. Instead, the company attempted to extinguish the fire by cutting off air inflow into the shaft, but the fire continued to rage. On October 23, a week after the accident, water was injected while the safety of the 59 miners trapped in the shaft remained unknown. At that time, a moment of silence was observed throughout the mining region's whole population, including at schools.

As a result, the Yubari Shintanko filed for application of the Corporate Reorganization Act in December 1981 under a heavy debt load and started to explore ways of business reconstruction. At the end of January 1982, the company resumed production after an interval of 103 days. By the end of March, all remaining bodies were recovered. However, the path to business reconstruction was difficult. In August, the administrator notified the labor union of the closure of the mine, and on October 9, the mine was closed, resulting in the dismissal of 1,905 employees. This gas outburst accident was very impactful in that it was not only a tragic incident that caused many deaths but also an accident that doomed the expectation of the coal industry, the miners and their families.

Table 1. From development of the Yubari Shintanko to the accident.

\begin{tabular}{lll}
\hline Year & \multicolumn{1}{c}{ Date } & \multicolumn{1}{c}{ Incident } \\
\hline 1970 & October & The development started. \\
\hline 1975 & June & Commercial coal production started. \\
\hline 1981 & October 16 & A gas outburst and a fire occurred. \\
\hline & October 17 & $\begin{array}{l}\text { The president proposed to inject } \\
\text { water. }\end{array}$ \\
\hline & October 23 & Water injection started. \\
\hline December & $\begin{array}{l}\text { The president attempted suicide at } \\
\text { Hokutan's head office in Tokyo. }\end{array}$ \\
\hline $\begin{array}{l}\text { December } \\
\text { 15 }\end{array}$ & $\begin{array}{l}\text { The company filed for application of } \\
\text { the Corporate Reorganization Act. } \\
\text { At the end } \\
\text { of }\end{array}$ & $\begin{array}{l}\text { The Hokkaido Teachers Union } \\
\text { donated collected money and school } \\
\text { supplies to Yubari City. }\end{array}$ \\
\hline January 27 & $\begin{array}{l}\text { Production was resumed after an } \\
\text { interval of 103 days. }\end{array}$ \\
\hline February & $\begin{array}{l}\text { Students at Shimizusawa Junior High } \\
\text { School wrote essays }\end{array}$ \\
\hline March 28 & $\begin{array}{l}\text { The remaining 15 bodies were } \\
\text { recovered. } \\
\text { Ahe administrator notified the labor } \\
\text { union of the closure of the mine. }\end{array}$ \\
\hline October 9 & \begin{tabular}{l} 
The mine was closed \\
\hline
\end{tabular}
\end{tabular}




\section{Data and Hypotheses}

\subsection{Data: The Yubari Shintanko disaster and us}

This paper analyzes essays written by junior high-school students at the time of the fatal accident at the Yubari Shintanko. The essays concerning the accident were written in February 1982, around four months after the disaster, by all students at Shimizusawa Junior High School. Most of the students were children of miners at the Yubari Shintanko. As shown in Table 2, the collection of essays comprised those written by 578 students in the seventh to ninth grade, including 14 students who lost their fathers in this accident. This collection of essays is stored at the Yubari History and Education Data Room, which is managed by the Yubari City Education Board. The Board gave us the approval for analyzing it exclusively for the purpose of research.

Table 2. Number of writers of the essay.

\begin{tabular}{ccr}
\hline Grade & $\begin{array}{c}\text { Number of } \\
\text { writer students }\end{array}$ & $\begin{array}{c}\text { Number of } \\
\text { bereaved children }\end{array}$ \\
\hline Seventh & 176 & 7 \\
\hline Eighth & 213 & 4 \\
\hline Ninth & 189 & 3 \\
\hline Total & 578 & 14 \\
\hline
\end{tabular}

\subsection{Analysis method and hypotheses}

In Japanese coal-producing regions, there are many cases in which elementary and junior high-school students wrote essays about coal mines, particularly concerning mine closure. Although these essays are valuable for identifying not only the subjective reality of children but also the situations of the local communities and families, they have not been sufficiently analyzed from the viewpoints of social sciences.

In the meantime, a sociological study has been ongoing in recent years concerning the case of the Shakubetsu coal mine (located in the former Onbetsu Town, eastern Hokkaido; closed in 1970). Shindo (2016) analyzed essays written by local junior high school students at the time of the mine closure and letters written after their departure from the mine community and showed that the students were significantly affected by the mine closure and rapid decline of the community (all residents left the community within one year from the mine closure). Specifically, the children felt anxiety about the future due to the mine closure and their career aspirations and perception of society changed. While they were also worried about adapting to urban life after leaving the mine community, they showed readiness to make efforts to overcome the challenge. Meanwhile, Naoko Shimazaki (2016) put the above finding in a multidimensional context and went on to explain that it shows a "characteristic and strength particular to children in their junior high school days" who are about to face a career choice, a period when they are most sensitive (Shimazaki 2016).

As mentioned in the introduction, life course studies in North America have focused the relation between children and social change. These studies observed the influences of the Great Depression on the children's lives at the time and their later lives. In conclusion, they revealed that children changed their career vision and social attitude by experiencing the social change through their families (for example, unemployment and economic hardship) (Elder 1974). Thus, this paper tries to reveal the influence of the Yubari Shintanko accident on the children's lives, using the life course approach.

This paper's subject is not children's experience of a mine closure but their experience of a mine accident and the period of time in question is also different from when the Shakubetsu mine was closed, but it is expected that both common effects and effects particular to each case will be found. Therefore, this paper verifies the following two hypotheses. The first hypothesis, which pays attention to the timing of the disaster in the children's life course-junior high school days - is that although the children who experienced the disaster felt anxiety about the future and their career aspirations and perception of society changed, they gradually understood the circumstances and resolved to go forward toward the future. The second hypothesis, which pays attention to the contexts of the Yubari Shintanko and the Yubari region, is that as the children had high expectations for the Yubari Shintanko, they expected the accident to lead to the closure of the mine and the decline of Yubari community and they also tended to envision their own future outside Yubari.

\section{Analysis \\ 4.1 Anxiety and changes in perception}

Most of the essays written by the 578 students describe the situation from the occurrence of the accident onwards in a time-sequential order.

\section{(i) The Day of the Accident and the following day}

On the day of the accident, the children learned of the disaster after school hours. A seventh grader wrote: I left school in a hurry. Instead of going home, I started running in the direction of the pithead to see my father (a girl in the seventh grade). Fortunately, this student's father was alive and well. However, on the day of the accident alone, 32 bodies were recovered, including the fathers of some school children. An eighth grader who lost her father recalled of the day of the accident in her essay as follows: I knew it was not impossible but... My father is one of those who lost their lives in this disaster. I was nagged by the thought of how I should live from now on (a girl in the eighth grade). This student could not easily understand the death of her father, and she was feeling strong anxiety about the future.

On the day after the accident, children whose fathers remained alive and well attended class but those who lost their fathers were absent. A ninth grader who went to school on that day recalled: Thinking of the people who were absent, my tears did not stop flowing. The presence of vacant desks seen here and there loomed very large (a girl in the ninth grade). This indicates that children whose fathers escaped the disaster were also feeling sorrow. 
From the day after the accident onwards, various possibilities, such as mine closure, school transfer and giving up on advancing to high school, became the main topics of talk among the children. A ninth grader facing a career choice wrote: As a variety of speculation was circulating, we were mainly saying things like "half of the class may have to change schools" or "it may be difficult to advance to high school" on that day (a boy in the ninth grade). The children were already aware that this disaster was not just an ordinary accident but one that would significantly influence their future.

\section{(ii) A week after the accident}

The company injected water into the shaft a week after the accident in order to extinguish the fire. This came as a huge shock for the children. A seventh grader who until then had been hoping for his father's survival wrote the following sentences: When the president said, "I would like to inject water," I could no longer forgive him. I thought, "Injecting water while there are survivors in the shaft is in no way acceptable," and I felt sick. I wanted to say to him, "What do you take my father for?" But after all, water was injected into the shaft. "Damn the president...," I thought. At that moment, my hopes finally disappeared (a boy in the seventh grade). From this essay, we can see that the presentation and implementation of the proposal to inject water while miners remained in the shaft increased children's hostility to the company and the president.

(iii) Two months after the accident

In their essays, the children referred to the criticism that they directed at the president when he attempted suicide in December. A ninth grader wrote: Is he trying to make trouble again? I would like him to refrain from taking irresponsible actions (a boy in the ninth grade).

Also in December, the company filed for application of the Corporate Reorganization Act. Viewing this as a substantive bankruptcy, the children felt renewed anxiety about the future. A ninth grader wrote of her feelings at the time as follows: As if to add salt to the injury after the accident, the substantive bankruptcy came. "No way!" was my reaction, as I was filled with feelings of disbelief, all the more so because we had until then been trying to help rebuild the company (a girl in the ninth grade). This is an indication that the children could not accept the substantive bankruptcy because they expected the rebuilding of the Yubari Shintanko to lead to the recovery of Yubari community. The movements of the president and the company around that time were a factor that caused the children to feel increased anxiety about the future, including the prospect of the mine being closed or of having to change schools.

\section{(iv) Three months after the accident}

However, at the end of January, three months after the accident, the Yubari Shintanko partially resumed production. This gave the children some expectation. Expressing expectations for the rebuilding of the Yubari Shintanko and the revitalization of Yubari community, an eighth grader wrote: Now, the operation started in the northern area. I am hoping that the mine will be somehow rebuilt and bring vitality to Yubari community as a coal community (a boy in the eighth grade).

However, because of a delay in the salary payment for January, the children felt renewed anxiety. Describing the concern about life, a ninth grader wrote as follows while making a reference to their mother's worries: The salary is usually paid on the 20th day of the month but it was delayed to the 29th day this month, so my mother is very much worried whether the salary will be paid in February and March (a boy in the ninhth grade).

As shown above, the children vividly remembered the events that occurred in the four months since the accident and described them in their essays. The children felt anxiety about these events and their perception of society changed.

\subsection{Changes in the perception of the Yubari Shintanko and Yubari community}

The children made references to the impact of this accident on the Yubari Shintanko and Yubari community as they recalled the sequence of events since the accident. Particularly notable were observations that the accident would lead to the closure of the Yubari Shintanko and the decline of Yubari community.

\section{(i) Concerning the closure of the mine}

First of all, the children were worried that the accident might lead to the closure of the mine. As mentioned earlier, the possibility of a mine closure already became a topic of talk at school on the day after the accident and their worry persisted subsequently. A ninth grader wrote as follows: Because of the coal mine accident, the community that was previously peaceful has now changed rapidly and sank to the bottom of unhappiness and sorrow. In addition, the Yubari people's mood is shrouded in anxiety. There are problems that we until now thought had nothing to do with our lives. Various events are happening at the same time, and things are going along as we children remain unable to do anything (a girl in the ninth grade). As shown in this essay, the children were aware that the mine closure, which they had not imagined at all before the accident, was about to become a reality because of the disaster. In addition, the students felt their own helplessness as children, as they encountered various events about which they were unable to do anything.

Moreover, as already mentioned, some children had already experienced a mine closure and changing of schools. They were more sensitive than other children to a mine closure and associated the accident with the mine closure. An eighth grader who had experienced a mine closure while at kindergarten, wrote as follows: I absolutely hope that a mine closure will never happen. That is because I experienced a mine closure once. The class of 35 children shrank to around 18 children several months later. At that time, I hated it very much. I felt very sad at the thought of my close friends going to faraway places. (a girl in the eighth grade). This girl recalled the mine closure and described those memories as an experience that she did not 
want to repeat. The accident at the Yubari Shintanko was an event that reminded her of her previous experience of a mine closure and also led her to see the possibility of the Yubari Shintanko being closed.

\section{(ii) Decline of Yubari community}

The children assumed not only that the accident would lead to the closure of the mine but also that it would cause or was already causing the decline of Yubari community. Realizing the population decrease, a ninth grader expressed expectations that Yubari community would decline in the future: Since that terrible accident, Yubari's population has continued to decline, so I am always filled with concern that Yubari City could be downgraded to a town or perhaps even a village sometime in the future (a girl in the ninth grade). While the population decrease indeed became prominent around the time of the mine closure (October 1982), the population appeared to the children to be decreasing more than was actually the case, causing them to expect that Yubari community would decline if this trend continued. As a result, they had serious concerns over the possible decline of their home town.

Another student asserted that the accident determined the decline of Yubari community and that there was no solution: I don't know whether I should write things like this, but I think that there is no prospect for the Yubari Shintanko. I expect that this accident will dramatically change Yubari community from now on. Even though the accident has passed, what has been left in people's hearts will never disappear. I think there is nobody who can save Yubari community now (a girl in the eighth grade). As shown in this essay, this student was expecting that Yubari community would sink into gloom in the future because there was nobody who can save Yubari as the prospects for the mine that was the expectation of the community were dim.

As indicated above, the children concluded that this accident had determined the closure of the Yubari Shintanko and the decline of Yubari community and described their conclusion in their essays. That was not only because of the appalling nature of the accident but also because the Yubari Shintanko was the expectation of the community and the children were in their junior high school days, a sensitive period in life.

\subsection{Changes in perception of the future}

In anticipation of the closure of the mine and the decline of Yubari community, the children felt anxiety about their own futures. In particular, they were worried about their career prospects - whether they would advance to high school or start working - and about relocation.

\section{(i) Changes in career aspirations}

In 1981, the high school enrollment rate in Yubari City was higher than $90 \%$ (Hokkaido, 1982), so advancing to high school was the standard course for most children. However, having experienced the accident and the subsequent turmoil, some students, mainly ninth graders, found it difficult to make up their mind as to their life course after graduating from junior high school. A ninth grader wrote: As the
Yubari Shintanko has gone bankrupt, I am often thinking of giving up on advancing to high school and starting to work and I have consulted with my mother (a boy in the ninth grade). Another ninth grader, expecting that he would continue to worry after advancing to high school, wrote: Even if I am accepted into high school, I am really very worried what I should do if the Yubari Shintanko is closed and if my father is forced to go somewhere else (a boy in the ninth grade).

This accident also raised concerns about the life course after graduation from high school. An eighth grader voiced concern about commuting, including to university: Some people will advance to high school and then to university. Is it possible to continue to live with a peaceful mind in this region until then? That is what worries me (a girl in the eighth grade).

The perceptions on working and occupations of a ninth grader whose father is a rescuer changed as shown in the following sentences: What I thought after this terrible accident is that public-sector occupations such as teachers and civil servants involve few life-threatening jobs and are stable. I also intend to choose a secure, stable occupation when making the choice (a boy in the ninth grade). As is clear from this essay, the accident at the Yubari Shintanko raised children's awareness about the very dangerous nature of the work in a mine. Moreover, the preference for stable occupation indicates that through the accident, the children realized not only the danger of a mine but also the instability of the work in a mine as an occupation. This is a viewpoint unique to the sensitive junior high school students who are about to face a career choice.

(ii) Changes in the attitude to relocation

The children's attitude to relocation also changed. Usually, advancing to high school in Yubari City would have been the standard. However, after the accident, some children became eager to leave Yubari City when starting to attend high school. A ninth grader who was eager to go somewhere else described the difference between his and his father's thoughts in his essay: If the Yubari Shintanko goes bankrupt, my father says he will "remain in Yubari City and find a job and continue to live here." Frankly speaking, I don't want to remain in Yubari City. If possible, I would like to move to some other town (a boy in the ninth grade). One reason why fathers, unlike children, preferred to remain in Yubari City is that the special nature of the work in a mine made it difficult to find a new job (switch to a job in a different industry) (Takahashi (ed.) 2002, Shimazaki 2015). As there was still a handful of other mines in Yubari City (for example, Hokutan Mayachi, Mitsubishi Minami Oyubari), there was still a chance to return to working in a mine. As the children were not considering working in a mine, they naturally preferred to go somewhere else.

Some children indicated in their essays their expectation to leave Yubari City in the future when starting work after graduating from high school. Expressing such expectation, an eighth grader wrote: As jobs in Yubari City will disappear, I will find an urban job. By then, Yubari City may disappear (a boy in the eighth grade). For the children, 
the accident at the Yubari Shintanko raised expectations that Yubari City would lose its labor-absorbing capacity and would become a deserted town.

As described above, the children's career aspirations and attitude to relocation changed after the accident. The children were expecting to leave Yubari City, which was likely to decline, when advancing to high school or university or when starting to work.

\section{Conclusions}

The above analysis results mostly verify the two hypotheses that were presented earlier. Concerning the first hypothesis, the children who experienced the accident at the Yubari Shintanko felt anxiety about the future, and their career aspirations and perception of society changed. Not only children who lost their fathers but also children whose parents remained alive and well were affected by various events that occurred in the four months between the accident and the writing of the essays. The accident's impact on the children was so significant not only because of its appalling nature but also because they were in their junior high school days, a sensitive life stage. This is a trend that was also observed among the children in Shakubetsu. The difference is that the process of overcoming anxiety was not so apparent in Yubari. This was because when the children in Yubari wrote their essays, it was four months after the accident and eight months before the mine was closed, which means that they were trapped in the mixture of the trauma of the disaster and worry over the dismal prospect of the mine closure.

Concerning the second hypothesis, the children who experienced the accident at the New Mine associated the accident and the mine closure directly with the decline of Yubari community all the more because their expectations for the mine were high. The children, especially those who had moved from other mines, realized that the accident would lead to the closure of the mine and cause the decline of Yubari community. Consequently, they expected to leave Yubari City in the future while feeling anxiety about their life course and relocation. Anxiety about the future was also observed among the children in Shakubetsu. However, the children in Yubari felt strong anxiety about a change in the life course (start working after graduating from junior high school) because advancing to high school was the standard around the time when they were about to graduate (in the first half of the 1980s).

As described above, this paper revealed that the accident at the Yubari Shintanko had a significant shortterm impact on the children. Going forward, the challenge is conducting analysis by gender and class and closely examining the medium and long-term impacts.

As described in the children's essays, the accident became a turning point that determined the decline of Yubari community. The Yubari Shintanko was closed only one year after the accident. The expectation of the Japanese coal industry and Yubari community disappeared in just seven years. Later, other coal mines in Yubari coal field were closed one after another, and each time, people migrated out of the city, with many children moving to schools elsewhere. As Yubari City lost mines and the youth population, its fiscal condition deteriorated further, resulting in the fiscal collapse in 2007.

The quest still continues for ways of putting Yubari community on the path of recovery. Yubari City has worked to sustainable development from 1990s onward. The City has tried to create the new industry (for example, Yubari melon farming and tourism), but they have been not going so far. At present, the City brings the youth back and tries to train them to the leaders of town revitalization, but these challenges don't make it difficult to create attractive employment opportunities.

\section{Acknowledgement}

The authors would like to thank the reviewers for their comments and contribution to improve this paper.

\section{References}

Clausen, J., 1986. The life course: A sociological perspective. New Jersey, Prentice Hall.

Elder, G.H. Jr., 1974. Children of the great depression: Social change in life experience. The University of Chicago, Chicago.

Masaoka, K., J. Hujimi, N. Shimazaki and K. Sawaguchi, 1998-2007. Tanko rodosya no heizan risyoku to career no saikeisei, I-V. The University of Waseda Faculty of Letters, Tokyo. (Japanese)

Hokkaido, 1959-1975. Hokkaido tokeisyo. (Japanese)

Hokkaido, S. (eds), 2003. Tanko: Seisui no kioku. (Japanese)

Hokutan Yubari Coal Mine Labor Union, 1983. Kaisan kinenshi: Kyosyu. (Japanese)

Seiryo Elementary School, 1971. Shinko. (Japanese)

Shimazaki, N., 2015. Support for workers displaced in the decline of the Japanese coal industry: Formal and informal support. Japan Labor Review, 12(2): 6 - 27.

Shimazaki, N., 2016. Syakubetsu tanko no heizan to kodomotachi kara manabukoto. JAFCOF Kushiro Research Paper, 7: 41 - 46. (Japanese)

Shindo, K., 2015. Santanchi ni okeru kodomo no sugata to kyoiku zissen: 1950 - 1960 nendai zenhan no kenkyu wo motonishite. Gunma Daigaku Kyoiku Zissen Kenkyu, 32: 123 - 134. (Japanese)

Shindo, K., 2016. Tanko heizan ga motarasu kodomo no seikatsu to ishiki no henyou: syakubetsu tanko heizan zengo no tyugakusei no sakubun tegami wo tuzite. JAFCOF Kushiro Research Paper, 9: 1 - 24. (Japanese)

Takahashi, S. (eds), 2002, Ido Syakai to Seikatsu Network, Osaka, Takasuga Syuppan. (Japanese)

Yada, T., 1983. Hokutan yubari shintanko no heizan to chiiki keizai. Chiri, 28(3): 81 - 90. (Japanese)

Yubari City, 1981. Yubari shi shi. (Japanese) 